\title{
Clinical heterogeneity of low flow spinal arteriovenous fistulas; a case series
}

\author{
D. Krishnan ${ }^{1 *}$, S. Viswanathan ${ }^{1}$, N. Rose ${ }^{2}$, H. S. N. Benjamin ${ }^{1}$, A. M. Ong ${ }^{1}$ and F. L. Hiew ${ }^{1}$
}

\begin{abstract}
Background: Spinal AVF (SAVF), a potentially treatable cause of myelopathy, remains a challenging diagnosis. Its rarity and non-specific imaging findings often result in misdiagnosis despite a high index of clinical suspicion. The classically described high T2 signal in the spinal cord or prominent vascular flow voids in the intradural space were not infrequently missed on initial imaging, only to be picked up at follow-up imaging after progression of symptoms. Additionally, small sized fistulas $(<1 \mathrm{~mm})$ and SAVF involving less frequent locations like the craniocervical junction in a patient presenting with paraplegia further complicates the diagnosis. On rare occasions, acute atypical presentation following a surgery adds to the conundrum. Definite diagnosis with spinal angiography, the gold-standard modality requires the expertise of highly skilled interventionists which may otherwise lead to false negative findings. We describe four SAVF patients with unconventional presentations, highlighting less described clinical findings.
\end{abstract}

Case presentation: First was a 50-year-old man presented with spastic paraparesis and was found to have an AVF at the cervical region arising from the vertebral artery. Second, a 45-year-old man with acute paraplegia postoperatively, initially treated for a transverse myelitis before lumbar region AVF was detected. Thirdly, a 27-year-old man presented with subacute lower thoracic myelopathy and deteriorated after corticosteroid treatment. The last patient, who initially appeared to have conus medullaris/cauda equina syndrome had a SAVF at the mid thoracic level. Presentation varied with some exhibiting acute deterioration mimicking other spinal cord pathology such as inflammatory disorders. All patients eventually underwent endovascular treatment with successful embolization of SDAVF. None of them exhibited further neurological deterioration after embolization.

Conclusion: Successful treatment of SAVF is possible provided the diagnosis is made early, allowing timely intervention. Certain clues may aid the diagnosis. Firstly, arteriovenous fistula can be located distant to the clinical localization of myelopathy resulting in the unexpected longitudinally extensive spinal cord signal change. This clinical-radiological discrepancy can be a useful clue in diagnosing SAVF. Secondly, an acute myelopathic presentation immediately post-surgery may be related to SAVF. Other SAVF feature of note includes progressive myelopathy mimicking immune-mediated myelitis among young adults below 30 years of age refractory to immune therapy.

Keywords: Spinal arteriovenous fistula, Low-flow, Clinico-radiological mismatch, Case series

\footnotetext{
* Correspondence: kdhayalen@yahoo.com

This work was performed in the Department of Neurology, Kuala Lumpur Hospital, Kuala Lumpur, Malaysia.

'Department of Neurology, Hospital Kuala Lumpur, Jalan Pahang, 50586, Kuala Lumpur, Malaysia

Full list of author information is available at the end of the article
}

(C) The Author(s). 2021 Open Access This article is licensed under a Creative Commons Attribution 4.0 International License, which permits use, sharing, adaptation, distribution and reproduction in any medium or format, as long as you give appropriate credit to the original author(s) and the source, provide a link to the Creative Commons licence, and indicate if changes were made. The images or other third party material in this article are included in the article's Creative Commons licence, unless indicated otherwise in a credit line to the material. If material is not included in the article's Creative Commons licence and your intended use is not permitted by statutory regulation or exceeds the permitted use, you will need to obtain permission directly from the copyright holder. To view a copy of this licence, visit http://creativecommons.org/licenses/by/4.0/. The Creative Commons Public Domain Dedication waiver (http://creativecommons.org/publicdomain/zero/1.0/) applies to the data made available in this article, unless otherwise stated in a credit line to the data. 


\section{Background}

Spinal arteriovenous fistulas (SAVFs) is a rare but treatable cause of chronic myelopathy as a result of progressive spinal venous hypertension. Available evidence suggests that SAVFs are acquired lesions due to obstructed spinal venous drainage although the actual etiology remains unclear. Despite increasing recognition of this disease and advancing surgical skills over the recent years, the diagnosis of complex SAVFs involving the low-flow fistulas especially at less common sites with atypical clinical presentation and non-specific spinal cord imaging appearance remains a challenge. SAVFs involving the craniocervical junction are rare, but are the most dangerous among all due to their potential significant brainstem oedema secondary to venous congestion. This can lead to an increased risk of subarachnoid or posterior fossa haemorrhage $[1,2]$. Very often, this variant of SAVFs is misdiagnosed even among experienced clinicians [3]. Unlike the high-flow pattern of other spinal vascular malformations, in which enlargement of perimedullary and/or epidural veins are readily identified by MRI imaging, the low-flow SAVFs are often missed or misdiagnosed due to a heterogenous spectrum of clinical presentation and non-specific appearance on imaging [4]. Common locations for low-flow SAVFs are perimedullary, epidural and dural [5]. A recent study on the sources of radiological error in diagnosing dural SAVFs found that over half of the radiologically confirmed cases were misinterpreted on initial MRI despite presence of typical imaging characteristics such as dilated veins, increased T2 signal and enlarged spinal cord segments [6]. There is no denying that the diagnostic process of this rare entity requires more than the standard routine imaging sequences.

We report 4 cases of low-flow SAVFs with longitudinally extensive, multi-segment lesions involving more than one spinal cord region. The atypical clinical course and imaging characteristics discussed unveils the paradigm of clinical heterogeneity in a single entity.

The clinical characteristics, chronology of events and outcome of patients are summarised in Table 1.

\section{Case presentation}

Case 1

A 50-year-old man presented with progressive spastic lower limb paraparesis over 3 months associated with urination retention. Neurological examination revealed a sensory deficit below the T6 dermatome. MRI demonstrated intramedullary $\mathrm{T} 2$ hyperintensities extending from the medulla to $\mathrm{C} 7$ spinal cord with heterogenous contrast enhancement and cord expansion. Despite being negative for serum Aquaporin 4. (AQP4) IgG and cerebrospinal fluid (CSF) oligoclonal band (OCB), he was treated as immune-mediated longitudinal extensive transverse myelitis (LETM) with intravenous (IV) Methylprednisolone. Two days later, his weakness progressed to quadriparesis. He subsequently received 5 sessions of therapeutic plasma exchange (TPE), but showed no response. A repeat MRI/MRA of the spine revealed extension of the hyperintense lesion from pons to T1 level with cord expansion and anterior serpinginous flow void signals (Fig. 1a and b). Spinal angiogram confirmed a SAVF at left $\mathrm{C} 1$ level with a feeding artery from the meningeal branch of the left vertebral artery. Endovascular embolisation was attempted but was incomplete due to technical difficulties. Imaging was repeated in view of poor neurological recovery. MRI done a year later demonstrated worsening of SAVF with new abnormal dilated epidural vessels at C6 to T6 level. Despite successful surgical ligation, there was no satisfactory clinical improvement and his functional outcome remained poor.

\section{Case 2}

A 45-year-old gentleman with no prior illness was admitted for hemorrhoidectomy under general anesthesia. Immediately following surgery, he complained of bilateral lower limb weakness and numbness with difficulty passing urine. Clinical assessment revealed paraparesis and loss of sensation with sensory level below the L1 dermatome. MRI of the thoracic and lumbosacral spine revealed an intramedullary $\mathrm{T} 2$ hyperintense lesion extending from T6 to L2 vertebra level with cord expansion and minimal contrast enhancement. He was treated as LETM with 3 days of IV Methylprednisolone and was subsequently discharged. Despite initial improvement in lower limb power after 2 weeks, he remained dependent on a urinary catheter and required laxatives to aid bowel opening. His lower limb weakness worsened 1 month later. An urgent MRI of the whole spine showed similar findings. In addition to second course of IV Methylprednisolone, he received 5 cycles of TPE but showed minimal improvement. A year later, he presented again with worsening paraparesis. Repeat MRI revealed a lesion suspicious of SAVF at the L2 region (Fig. 2a and b). This was confirmed with a spinal angiography after which he underwent successful embolisation. Despite no further relapses, his neurological recovery was poor.

\section{Case 3}

A 27-year-old gentleman presented with acute bilateral spastic paraparesis and bowel/bladder dysfunction with a sensory level at T12. He had a similar presentation 2 years ago and was treated as immune-mediated LETM in another institution. Following a course of IV methylprednisolone and intravenous immunoglobulin (IVIG), he had partial recovery and was able to ambulate despite a right foot drop and required intermittent bladder catheterization. Upon admission to our center, an urgent 
Table 1 Clinical characteristics, chronology of events and outcome of patients

\begin{tabular}{|c|c|c|c|c|}
\hline Patient & 1 & 2 & 3 & 4 \\
\hline $\begin{array}{l}\text { Age at } \\
\text { presentation } \\
\text { (years) }\end{array}$ & 50 & 45 & 27 & 56 \\
\hline Sex & Male & Male & Male & Male \\
\hline $\begin{array}{l}\text { Symptoms } \\
\text { onset to } \\
\text { presentation }\end{array}$ & 3 months & 1 day & 2 weeks & 5 months \\
\hline Presentation & $\begin{array}{l}\text { Numbness and weakness of } \\
\text { both LL }\end{array}$ & $\begin{array}{l}\text { Numbness and weakness of } \\
\text { both LL }\end{array}$ & $\begin{array}{l}\text { Numbness and weakness of } \\
\text { both LL }\end{array}$ & $\begin{array}{l}\text { Acute urinary retention, back pain, } \\
\text { numbness and weakness of } L L\end{array}$ \\
\hline $\begin{array}{l}\text { Antecedent } \\
\text { event }\end{array}$ & None & Haemorrhoid surgery & None & None \\
\hline \multicolumn{5}{|c|}{ Clinical deficits on presentation } \\
\hline $\begin{array}{l}\text { Motor } \\
\text { deficit }\end{array}$ & LL spastic paraparesis MRC 3 & $\begin{array}{l}\text { LL spastic paraparesis } \\
\text { MRC } 1\end{array}$ & $\begin{array}{l}\text { LL spastic paraplegia } \\
\text { MRC } 4\end{array}$ & $\begin{array}{l}\text { LL spastic paraparesis } \\
\text { MRC } 3\end{array}$ \\
\hline $\begin{array}{l}\text { Sensory } \\
\text { level }\end{array}$ & T6 & L1 & $\mathrm{T} 12$ & $\llcorner 4$ \\
\hline $\begin{array}{l}\text { Bladder } \\
\text { involvement }\end{array}$ & Yes & Yes & Yes & Yes \\
\hline $\begin{array}{l}\text { Bowel } \\
\text { involvement }\end{array}$ & Yes & No & Yes & No \\
\hline \multicolumn{5}{|c|}{ Clinical deficits at maximum severity } \\
\hline $\begin{array}{l}\text { Motor score } \\
\text { (MRC) }\end{array}$ & MRC $0 / 5$ & MRC 0/5 & MRC 0/5 & MRC 0/5 \\
\hline $\begin{array}{l}\text { Functional } \\
\text { score (MRS) }\end{array}$ & MRS 5 & MRS 4 & MRS 3 & MRS 4 \\
\hline \multicolumn{5}{|c|}{ MRI scan findings } \\
\hline $\begin{array}{l}\text { Spinal cord } \\
\text { regions }\end{array}$ & Craniocervical & Mid thoracic to upper lumbar & $\begin{array}{l}\text { Mid thoracic to upper } \\
\text { lumbar }\end{array}$ & Mid thoracic to upper lumbar \\
\hline $\begin{array}{l}\text { Abnormal } \\
\text { signals }\end{array}$ & $\begin{array}{l}\text { Intramedullary } \\
\text { hyperintensities extending } \\
\text { from the medulla to the C7 } \\
\text { cord }\end{array}$ & $\begin{array}{l}\text { Intramedullary } T 2 / F L A I R \\
\text { hyperintensity extending from } \\
\text { T6 to } L 2\end{array}$ & $\begin{array}{l}\text { Intramedullary T2/Flair } \\
\text { hyperintensity from T7 to L1 }\end{array}$ & $\begin{array}{l}\text { Intramedullary T2 hyperintensity } \\
\text { from T6 to L1 with contrast } \\
\text { enhancement }\end{array}$ \\
\hline $\begin{array}{l}\text { MRI scan } \\
\text { findings on } \\
\text { maximum } \\
\text { disease } \\
\text { severity }\end{array}$ & $\begin{array}{l}\text { Centrally hyperintense lesion } \\
\text { extending from the pons } \\
\text { down to } T 1 \text { with cord } \\
\text { expansion. } \\
\text { Anterior serpinginous flow } \\
\text { void signals at the upper } \\
\text { cervical region }\end{array}$ & $\begin{array}{l}\text { Intramedullary T2/Flair } \\
\text { hyperintense lesion from T6 up } \\
\text { to L2 with cord expansion and } \\
\text { minimal contrast enhancement }\end{array}$ & $\begin{array}{l}\text { Intramedullary T2/FLAIR } \\
\text { hyperintense lesion with } \\
\text { patchy enhancement } \\
\text { extending from } T 7 \text { to L1 } \\
\text { spinal cord }\end{array}$ & $\begin{array}{l}\text { Intramedullary T2 hyperintensity } \\
\text { from T4 cord to the conus } \\
\text { medullaris with dilated spinal veins } \\
\text { seen most prominently from T10 to } \\
\text { L1 }\end{array}$ \\
\hline $\begin{array}{l}\text { Spinal } \\
\text { angiogram }\end{array}$ & $\begin{array}{l}\text { Dural fistula at left } \mathrm{C} 1 \text { level } \\
\text { with a likely feeding artery } \\
\text { from meningeal branch of } \\
\text { left vertebral artery }\end{array}$ & $\begin{array}{l}\text { Suspicious spinal dural } \\
\text { arteriovenous fistula (SDAVF) at } \\
\text { the L2 region }\end{array}$ & $\begin{array}{l}\text { Dural fistula at left L2 lumbar } \\
\text { artery }\end{array}$ & $\begin{array}{l}\text { Initial negative but repeated showed } \\
\text { SAVF from left 12th posterior } \\
\text { intercostal arteries and L1 lumbar } \\
\text { artery }\end{array}$ \\
\hline $\begin{array}{l}\text { Response to } \\
\text { steroid }\end{array}$ & Paradoxical worsening & Improvement & $\begin{array}{l}\text { Partial response initially with } \\
\text { paradoxical worsening }\end{array}$ & Paradoxical worsening \\
\hline $\begin{array}{l}\text { Outcome after } \\
\text { embolisation }\end{array}$ & No improvement & No improvement & Improvement & No improvement \\
\hline $\begin{array}{l}\text { Motor score } \\
\text { (MRC) }\end{array}$ & $\begin{array}{l}\text { LL MRC } 0 \\
\text { UL MRC } 4\end{array}$ & $\begin{array}{l}\text { LL MRC } 0 \\
\text { UL MRC } 5\end{array}$ & LL MRC 4 & LL MRC 1 \\
\hline $\begin{array}{l}\text { Functional } \\
\text { score (MRS) }\end{array}$ & MRS 4 & MRS 4 & MRS1 & MRS 4 \\
\hline
\end{tabular}

Abbreviations: MRC Medical research council, MRS Modified Rankin Scale, LL lower limbs, UL upper limbs, SAVF spinal arteriovenous fistula, SDAVF spinal dural arteriovenous fistula 


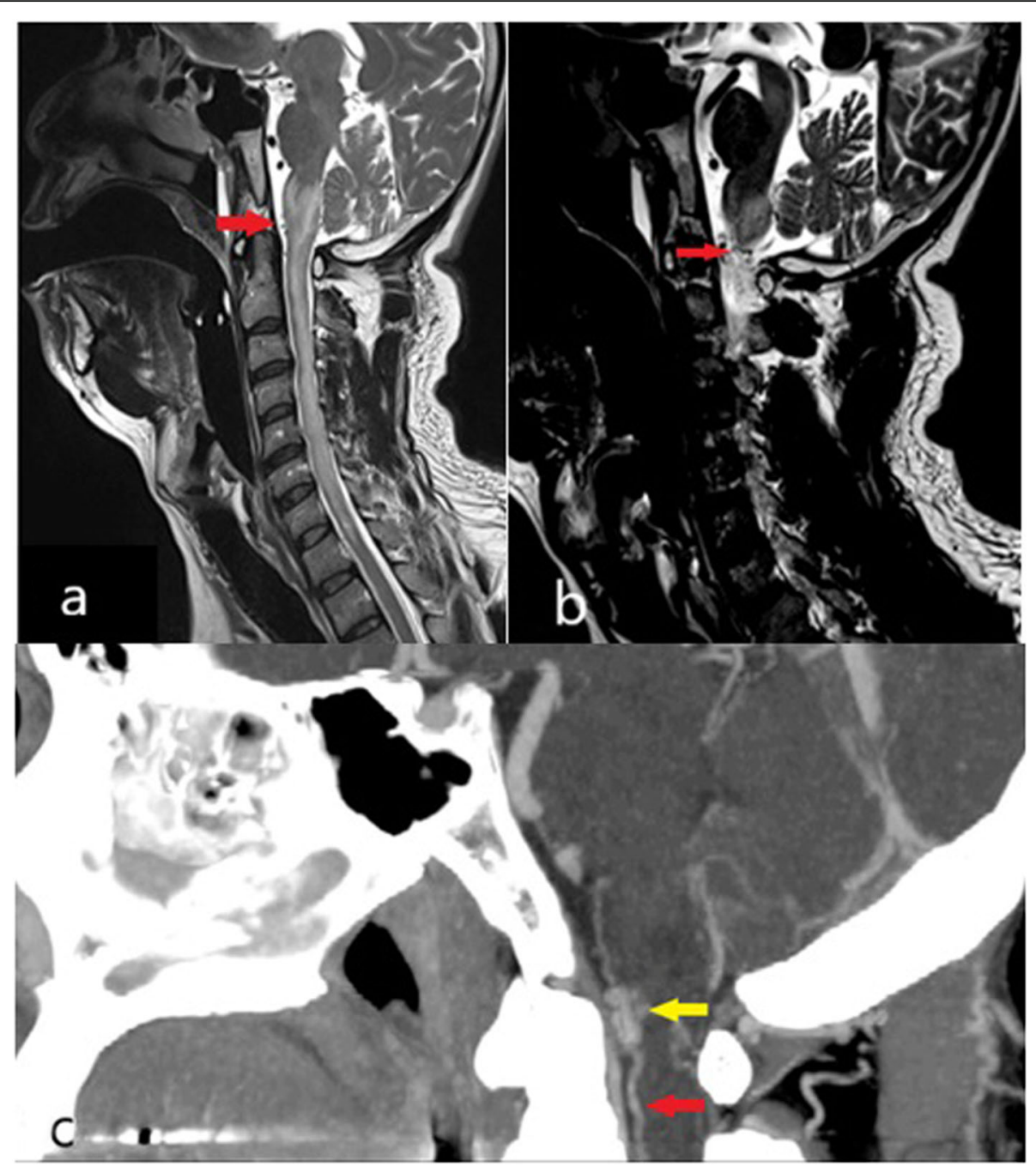

Fig. 1 a and $\mathbf{b}$ MRI of patient 1 demonstrated longitudinal extensive T2 hyperintensity from medulla to C7 spinal cord level with dilated perimedullary veins anterior to the cord at the cervical region (red arrow). c. CT angiogram demonstrated arterio-venous fistula (yellow arrow) at C1 level and the anterior dilated perimedullary veins (red arrow)

MRI of the spine reported a T2 hyperintense intramedullary lesion with patchy enhancement extending from T7 to L1. He rapidly deteriorated and became paraplegic over the next few days despite retreatment with IV Methylprednisolone. MRI images were revisited, with identification of flow void signals at the posterior aspect of the cord from T6 to L2 (Fig. 3a, b and c), which later confirmed a SDAVF at the L2 region on spinal angiogram. The patient underwent successful endovascular embolisation and showed good neurological recovery.

\section{Case 4}

A 56-year-old gentleman presented with a month history of lower back pain followed by paraparesis. Prior to that, he had an episode of acute urinary retention requiring temporary indwelling catheterization. MRI of the whole spine done at another center concluded degenerative spine disease. Upon assessment, sensation was reduced below the L4 dermatome. Repeat MRI showed a longitudinal extensive T2 hyperintense contrast enhancing intramedullary lesion from T6 to L1. His lower limb weakness deteriorated soon after the first dose of Methylprednisolone. Despite strong clinical suspicious of SAVF, his spinal angiogram was negative for this. He received a course of IV Methylprednisolone followed by plasmapheresis but showed no remarkable improvement. Within a year, he was readmitted twice for similar relapses and responded poorly to IV methylprednisolone. Repeated MRI spine demonstrated a worsening contrast enhanced T2 hyperintense lesion involving T4 to the conus medullaris with dilated spinal veins seen most prominently from T10 to L1 level (Fig. 4a and b). A 


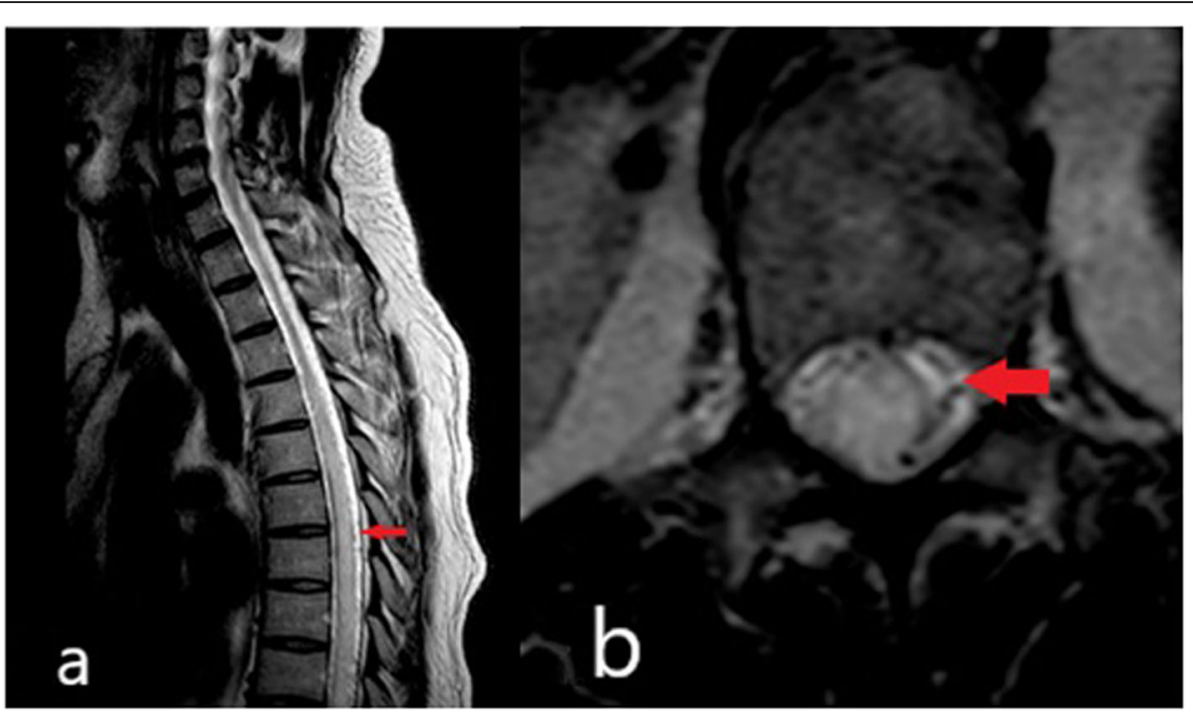

Fig. 2 a and $\mathbf{b}$ MRI of patient 2, showing the suspicious dilated vessels at the posterior aspect of the thoracic cord (red arrow)

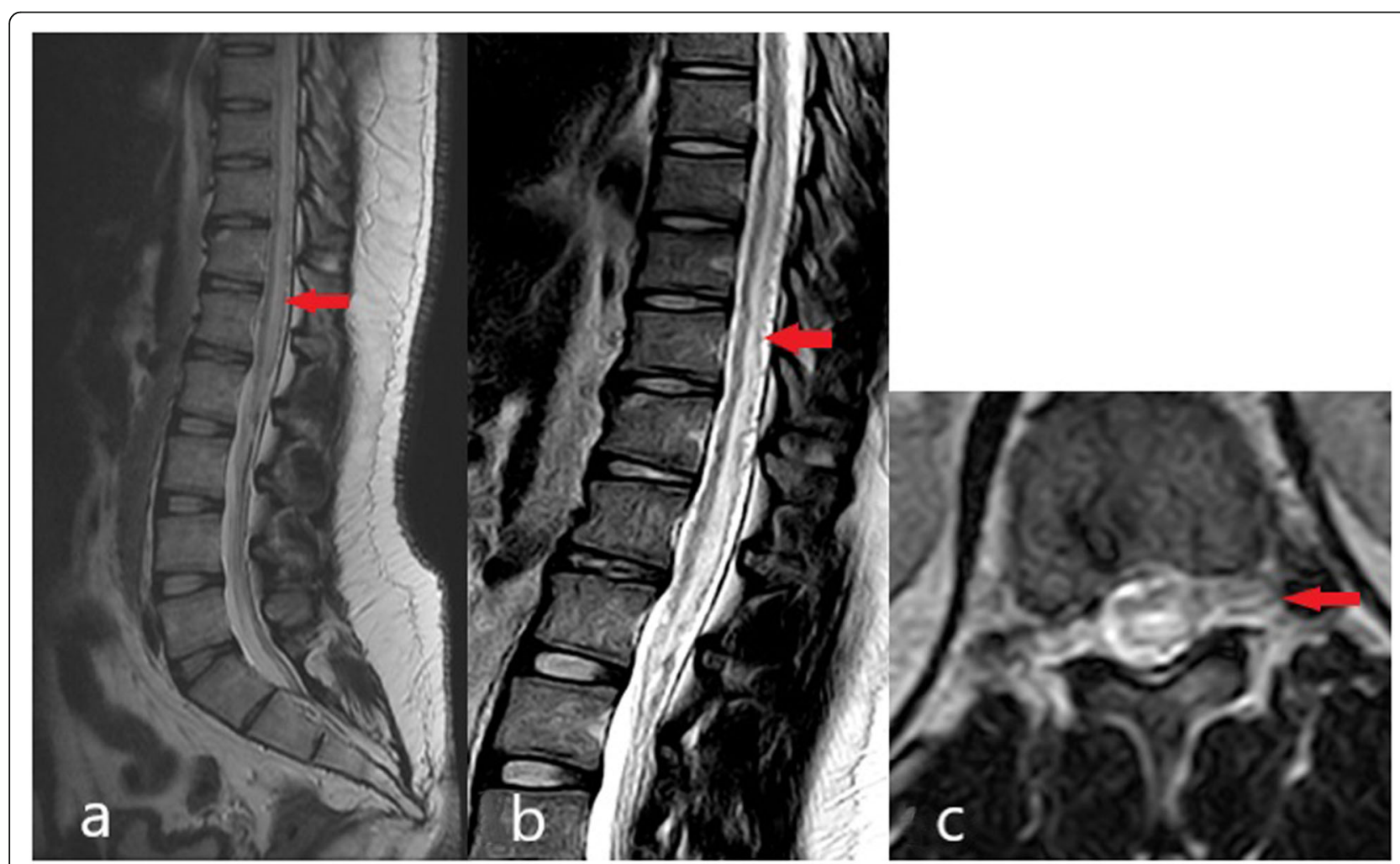

Fig. 3 a and $\mathbf{b}$ MRI of patient 3 demonstrated T2 hyperintense intramedullary lesion with patchy enhancement extending from T7 to L1 (red arrows) and features suspicious of SDAVF with the dilated vessels seen at the thoracolumbar spinal cord (red arrows). c. MRI which clearly shows the dilated vessels and the feeding vessel (red arrow) 


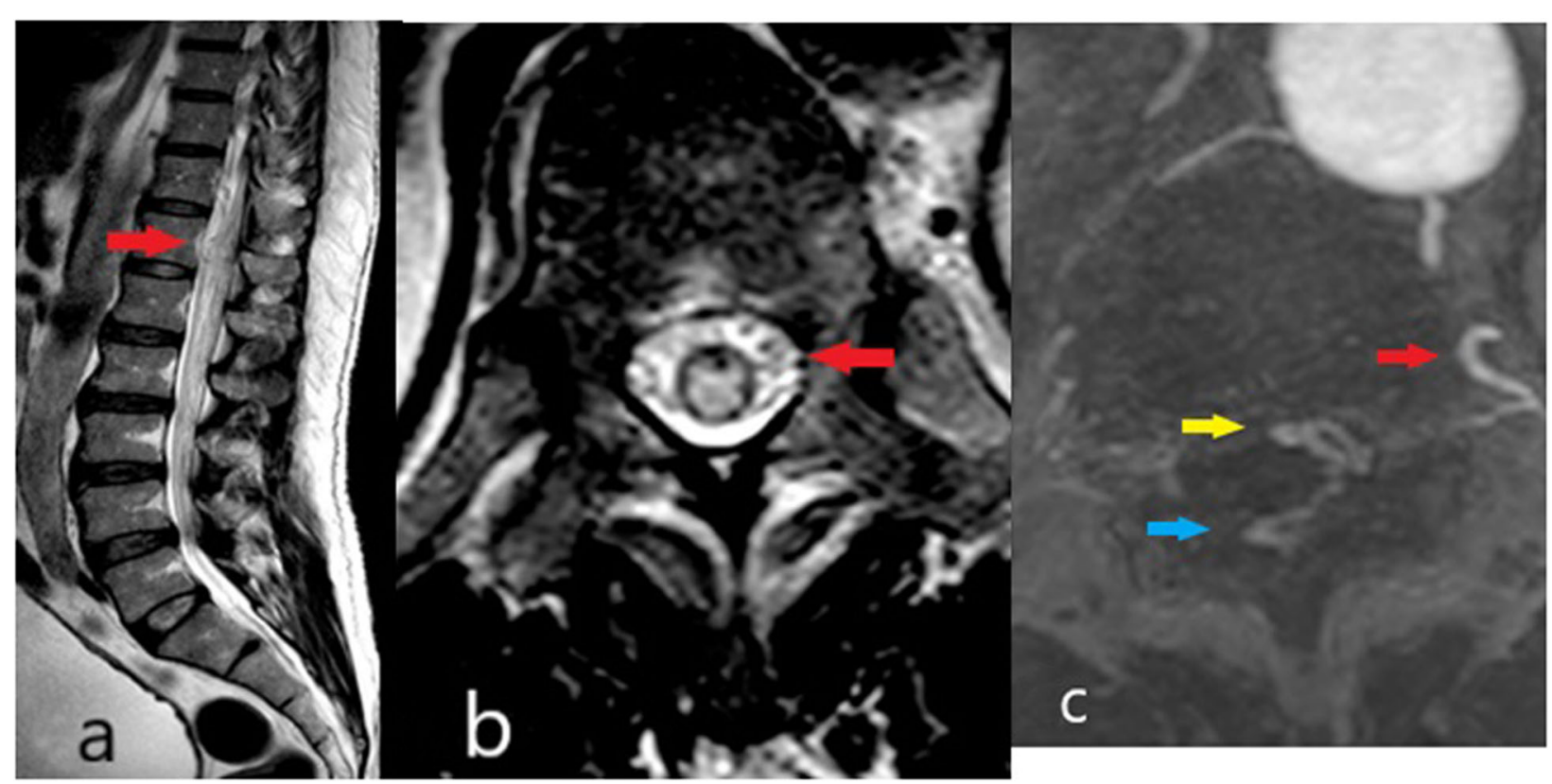

Fig. 4 a and $\mathbf{b}$ MRI spine of patient 4 showing the suspicious dilated vessels at the thoracolumbar cord (red arrow). c. CT angiogram (row below) demonstrated the feeding vessel (red arrow), dural AVF (yellow arrow) and the dilated perimedullary vein (blue arrow)

second spinal angiogram confirmed a SAVF with feeders from the left 12th posterior intercostal arteries and L1 lumbar artery. Despite successful embolisation, his neurological recovery was poor.

\section{Discussion and conclusion}

We described 4 cases of low-flow dural SAVFs with unique heterogeneous clinical spectrums. We discuss 4 important but less-described aspects of clinical practice in the management of SAVFs.

Firstly, the clinical presentation of the low-flow variant of SAVFs correlated poorly with radiological findings. Myelopathy and sensory deficit inaccurately predicted the extent of spinal cord intramedullary $\mathrm{T} 2$ signal and the level of SAVF. This was thought to be due to the unequal distribution of venous outflow channels along the spinal cord, with the lower thoracic region having relatively fewer venous outflow channels compared to the cervical region. This results in venous congestion being transmitted in a caudocranial direction, explaining the more severe myelopathy symptoms correlating with a more distal region of the MRI signal [7, 8]. This also explains why majority of the SAVFs involve the thoracolumbar region. Similarly, the rate of clinical progression and severity are independent of the length of abnormal spinal cord signal. Our patient with high cervical SAVF from a feeding artery that originated from the meningeal branch of the left vertebral artery was completely lacking brainstem signs as well as the commonly reported subarachnoid hemorrhage or intraparenchymal bleed within the brainstem [9]. The actual reason behind this is unclear. One study described five different types of craniocervical junction AVFs (Dural, Radicular, Epidural with pial feeders, Epidural and Perimedullary) based on location of the shunt point. The authors inferred that radicular type is more commonly associated with SAH besides other factors such as aneurysm of the feeder artery and anterior spinal artery as the feeder. All these features were not present in our patient [10]. The extent of spinal cord ischemia resulting in infarction likely plays a more important role than spinal cord oedema which is largely reversible [11]. From a recent analysis, symptoms of brainstem dysfunction are very rarely reported, occurring in only $3.3 \%$ of patients with craniocervical junction SAVFs [12]. This highlights the importance of careful imaging as a SAVF in a particular location may produce symptoms and signs further away as a result of intramedullary venous oedema [13]. This clinical-radiological discrepancy/mismatch may be an important clue to differentiate SAVFs from other causes of myelopathy.

Secondly, increased venous hypertension in low-flow SAVF reflects the underlying dynamic vascular pathophysiology of this disorder. Although the underlying aetiology and pathophysiology of SAVF is not perfectly understood, we know that arterialization of the venous system diminishes the arteriovenous pressure gradient and leads to a decreased drainage of normal spinal veins, resulting in venous congestion [7]. Therefore, any disruption around this arteriovenous system may result in SAVFs. In relation to this, we observed 2 unique events 
among our patients that could have led to the development of myelopathy. One of our patients developed symptoms following hemorrhoidectomy. To our knowledge, acute presentation post-operatively, and in our case, following hemorrhoid surgery, has not been reported. The pathogenesis of hemorrhoids is thought to be due to abnormal distension of the arteriovenous anastomoses within the hemorrhoidal cushions, in which part of the surgical treatment involves the ligation of hemorrhoidal arteries [14, 15]. It is still unclear if hemorrhoidectomy could affect the hemodynamics within the inferior vena cava (IVC) and the venous system, resulting in increased venous pressure at the spinal venous plexus contributing to an acute presentation in a patient with a pre-existing subclinical SAVF. Dural SAVF reported following spinal surgery such as correction of scoliosis and microdiscectomy for radiculopathy, further supports the postulation of an acquired traumatic or inflammatory mechanism $[16,17]$. Another patient of ours developed extensive dilated epidural vessels from C6 to T2 following an incomplete embolization of the left vertebral artery SAVF. Although this occurred after a year, it was not unusual. In majority of the patients, SAVFs, symptoms are usually slowly progressive over many months to years. Elswick and colleagues reported a case of dural SAVF that developed 5 years after thoracolumbar fusion for scoliosis [16].

Thirdly, majority of patients with SAVFs have MRIs that show either longitudinally extensive intramedullary T2 hyperintense signal, flow voids or cord expansion. The probability of one of these MRI changes occurring in a patient is reported to be as high as $100 \%$ [18]. Despite that, these features are frequently missed due to its rare occurrence [19]. Spinal angiogram is considered the gold standard investigation to confirm SAVFs [20]. However, no imaging modality has perfect sensitivity and specificity. A false negative spinal angiogram may further complicate clinical judgement. This could be due to misinterpretation of images, technical difficulties especially when involving small SAVF $<1 \mathrm{~mm}$ or limited spinal segments on angiogram study [3, 13, 20]. Highly specific angiographic techniques performed by experienced interventional specialists and meticulous analysis of angiographic images are essential for accurate diagnosis and identification of the location of the fistula $[3,4,20]$.

Lastly, low-flow SAVF is typically diagnosed among older patients presenting with a progressive myelopathy secondary to spinal venous hypertension. The diagnosis is extremely uncommon in the younger population and is rarely discovered before the age of 30, although one of our four patients was 27 years old. It is estimated that disease onset before 30 of age constitute less than $1 \%$ of the patients [7]. We could not identify any specific history or precipitating factors in this patient, but in comparison to the other 2 patients with relatively similar thoracolumbar SAVF presentation at maximum severity, the outcome post-embolization was far better. Although his presentation was relatively early within 2 weeks of symptoms onset, which has been associated with better long-term outcome [13, 21], similar outcome was not observed in case 2 with symptom onset posthemorrhoidectomy. From a recent analysis, patient's age and neurological status at diagnosis had no influence on the long-term outcome. This was in contrast to the conventional assumption that younger patients have better recovery potential and likewise, the more severe the neurological deficit, the poorer the recovery [21]. These observations reflected the ongoing lack of understanding of the disease.

Neurosurgery and endovascular embolization have been employed in the management of SAVF. Endovascular modality has been the traditional first line approach in our institution, possibly due to the limited expertise and risks involved with open spinal surgery. However, several studies and meta-analyses over the years have consistently shown better success and lower recurrence rates with neurosurgery compared to endovascular treatment; although the outcome of the latter has improved over time [22].

We described the atypical presentation and clinical heterogeneity seen among patients with low-flow SAVFs. Careful recognition of these uncommon features such as prominent high craniocervical lesions without brainstem signs, symptom onset in association with a recent surgery, false negative spinal angiogram, and SAVF in young adults may change the clinical course of the disease and improve functional prognosis.

\section{Abbreviations}

AQP4: Serum Aquaporin 4; CSF: Cerebrospinal fluid; IVIG: Intravenous immunoglobulin; IVC: Inferior vena cava; LETM: Longitudinal extensive transverse myelitis; MRI: Magnetic resonance imaging; OCB: Oligoclonal band; SAVFs: Spinal arteriovenous fistulas; TPE: Therapeutic plasma exchange

\section{Acknowledgements \\ The authors would like to acknowledge the interventional radiology team of our hospital for their invaluable contribution in managing the patients. We also would like to acknowledge the Director General of Health, Malaysia for allowing us to publish this work.}

\section{Authors' contributions}

All authors were involved in the patients' care. DK, SV, HSN and AMO identified the study subjects and collected the study data. FLH designed and conceptualized the study, analyzed data and drafted manuscript for intellectual content. NR provided the radiological images for all the patients. All authors made critical revisions and approved the final version to be published.

Funding

No funding was obtained for this study. 


\section{Availability of data and materials}

All relevant data are available at the Neurology clinic, Kuala Lumpur General Hospital.

\section{Declarations}

Ethics approval and consent to participate

Not applicable.

\section{Consent for publication}

Written consent taken from each patient to publish their clinical/personal details along with any identifying images in this article.

\section{Competing interests}

All authors declared no competing interests.

\section{Author details}

'Department of Neurology, Hospital Kuala Lumpur, Jalan Pahang, 50586, Kuala Lumpur, Malaysia. ${ }^{2}$ Department of Radiology, Hospital Kuala Lumpur, Kuala Lumpur, Malaysia.

Received: 9 September 2020 Accepted: 8 September 2021

Published online: 21 September 2021

\section{References}

1. Rangel-Castilla L, Russin JJ, Zaidi HA, Martinez-del-Campo E, Park MS, Albuquerque $F$, et al. Contemporary management of spinal AVFs and AVMs: lessons learned from 110 cases. Neurosurg Focus. 2014;37(3):18-20. https://doi.org/10.3171/2014.7.FOCUS14236.

2. Zhao J, Xu F, Ren J, Manjila S, Bambakidis NC. Dural arteriovenous fistulas at the craniocervical junction: a systematic review. J Neurointerv Surg. 2016; 8(6):648-53. https://doi.org/10.1136/neurintsurg-2015-011775.

3. Firsching R, Kohl J, Skalej M, Beuing O. Resolution of brainstem edema after neurosurgical occlusion of Dural arteriovenous fistulas of the Craniocervical junction: report of three cases and review. J Neurol Surgery, Part A Cent Eur Neurosurg. 2020;81(1):80-5. https://doi.org/10.1055/s-0039-1688560.

4. Murphy OC, Hedjoudje A, Salazar-Camelo A, Pardo CA, Gailloud P. Clinical characteristics, misdiagnosis and outcomes of patients with low-flow spinal arteriovenous fistulas. J Neurol Sci. 2020;413(April). https://doi.org/10.1016/j. jns.2020.116863.

5. Kang J, Gregg L, Gailloud P. Spontaneous resolution of low-flow spinal arteriovenous fistulas. Neuroradiology. 2017;59(10):1003-12. https://doi.org/1 0.1007/s00234-017-1888-x.

6. Hunt R, Roberts RM, Mortimer AM. Spinal dural arteriovenous fistula: delay to radiological diagnosis and sources of radiological error. Clin Radiol. 2018; 73(9):835.e11-835.e16. https://doi.org/10.1016/j.crad.2018.05.010.

7. Krings T, Geibprasert S. Spinal dural arteriovenous fistulas. Am J Neuroradiol. 2009:30(4):639-48. https://doi.org/10.3174/ajnr.A1485.

8. Koenig E, Thron A, Schrader V, Dichgans J. Spinal arteriovenous malformations and fistulae: clinical, neuroradiological and neurophysiological findings. J Neurol. 1989;236(5):260-6. https://doi.org/10.1 007/BF00314453

9. Zhong W, Zhang J, Shen J, Su W, Wang D, Zhang P, et al. Dural arteriovenous fistulas at the Craniocervical junction: a series case report. World Neurosurg. 2019;122:e700-12. https://doi.org/10.1016/j.wneu.2018.1 0.124 .

10. Hiramatsu M, Sugiu K, Ishiguro T, Kiyosue H, Sato K, Takai K, et al. Angioarchitecture of arteriovenous fistulas at the craniocervical junction: a multicenter cohort study of 54 patients. J Neurosurg. 2018;128(6):1839-49. https://doi.org/10.3171/2017.3.JNS163048 Epub 2017 Sep 1. PMID: 28862546.

11. Krings T, Lasjaunias PL, Hans FJ, Mull M, Nijenhuis RJ, Alvarez H, et al. Imaging in Spinal Vascular Disease. Neuroimaging Clin N Am. 2007;17(1):5772. https://doi.org/10.1016/.nic.2007.01.001.

12. Wang JY, Molenda J, Bydon A, Colby GP, Coon AL, Tamargo RJ, et al. Natural history and treatment of craniocervical junction dural arteriovenous fistulas. J Clin Neurosci. 2015;22(11):1701-7. https://doi.org/10.1016/j.jocn.201 5.05.014.

13. Ronald AA, Yao B, Winkelman RD, Piraino D, Masaryk TJ, Krishnaney AA. Spinal Dural arteriovenous fistula: diagnosis, outcomes, and prognostic factors. World Neurosurg. 2020;144:e306-15. https://doi.org/10.1016/i.wneu.2 020.08.126 Epub 2020 Aug 25. PMID: 32858225.
14. Morinaga K, Hasuda K, Ikeda T. A novel therapy for internal hemorrhoids: ligation of the Hemorrhoidal artery with a newly devised instrument (Moricorn) in conjunction with a Doppler flowmeter. Am J Gastroenterol. 1995:90(4):610-3. https://doi.org/10.1111/j.1572-0241.1995.tb09255.x.

15. Thomson WHF. The nature of haemorrhoids. Br J Surg. 1975;62(7):542-52. https://doi.org/10.1002/bjs.1800620710.

16. Elswick CM, Khalsa SSS, Saadeh YS, Pandey AS, Oppenlander ME. Spinal dural arteriovenous fistula formation after scoliosis surgery: case report. J Neurosurg Spine. 2020;32(1):144-9. https://doi.org/10.3171/2019.6.SPINE1 9323

17. Asakuno K, Kim P, Kawamoto T, Ogino M. Dural arteriovenous fistula and progressive conus medullaris syndrome as complications of lumbar discectomy. Case report. J Neurosurg. 2002;97(3 SUPPL):375-9. https://doi. org/10.3171/spi.2002.97.3.0375.

18. Toossi $S$, Josephson SA, Hetts SW, Chin CT, Kralik S, Jun P, et al. Utility of MRI in spinal arteriovenous fistula. Neurology. 2012;79(1):25-30. https://doi. org/10.1212/WNL.0b013e3182582f07 Epub 2012 May 16. PMID: 22592367.

19. El Mekabaty A, Pardo CA, Gailloud P. The yield of initial conventional MRI in 115 cases of angiographically confirmed spinal vascular malformations. J Neurol. 2017;264(4):733-9. https://doi.org/10.1007/s00415-017-8419-X.

20. Barreras P, Heck D, Greenberg B, Wolinsky JP, Pardo CA, Gailloud P. Analysis of 30 spinal angiograms falsely reported as normal in 18 patients with subsequently documented spinal vascular malformations. Am J Neuroradiol. 2017;38(9):1814-9. https://doi.org/10.3174/ajnr.A5275.

21. Jablawi F, Schubert GA, Dafotakis M, Pons-Kühnemann J, Hans FJ, Mull M. Long-term outcome of patients with spinal Dural arteriovenous fistula: the dilemma of delayed diagnosis. AJNR Am J Neuroradiol. 2020;41(2):357-63. https://doi.org/10.3174/ajnr.A6372.

22. Takai K, Endo T, Yasuhara T, Seki T, Watanabe K, Tanaka Y, et al. Neurosurgical versus endovascular treatment of spinal dural arteriovenous fistulas: a multicenter study of 195 patients. J Neurosurg: Spine SPI. 2021; 34(3):514-21 Retrieved Aug 21, 2021, from https://thejns.org/spine/view/ journals/j-neurosurg-spine/34/3/article-p514.xml.

\section{Publisher's Note}

Springer Nature remains neutral with regard to jurisdictional claims in published maps and institutional affiliations.

Ready to submit your research? Choose BMC and benefit from:

- fast, convenient online submission

- thorough peer review by experienced researchers in your field

- rapid publication on acceptance

- support for research data, including large and complex data types

- gold Open Access which fosters wider collaboration and increased citations

- maximum visibility for your research: over $100 \mathrm{M}$ website views per year

At BMC, research is always in progress.

Learn more biomedcentral.com/submissions 